\title{
BREATHE SOMETIMES
}

Joseph Ferron Hiatt

[A telephone play. The stage is black with a stand and bed. A figure lies on the bed. On the stand is a telephone answering machine. The only thing visible, lights on the machine flashing on and off, determine the action. The actor should not turn the machine on and off but should listen to it.]

[A phone rings six times. The machine answers and breathing is heard. Then a voice speaks from the machine.]

Every morning.

Every morning I recite to myself something hopeful-hopeful? Useful. Full of use-full of hope. Yes full of hope.

Rise!

Go out!

That's it —-that's all—it's usually all I need — of course sometimes I add to itlook sometimes - smile sometimes-force a smile sometimes...

...breathe sometimes.

But rarely. Rise is usually enough - the rest is insinuated - sometimes however it's not enough — no nothing is ever enough-I lie here naked staring toward the ceiling and nothing - nothing can stir me...

rise rise rise rise

Nothing-like a helpless Lazarus I lie here wondering if anything could have power enough to drag me from this rest—not that I rest- no, I rarely rest- 
or...feel rested. Sometimes I pull my hand up to where I can see it - closelyexamine it-try to stretch the fingers out all the way open-like yesterday-pick up! pick up! pick up!

Are you listening?

Then breathe some.

Thank you.

You're wondering - you're wondering why I'm going on like this...

Better? No, worse. Mindless prattle is better than stony silence. No worse. No speaking and one only hears breathing - breathing is the sound of a heartbeatbreathing is the bitch that beats the heart too close - too close of a sound to hear.

or not to hear.

None-the-less you're still here so I'll read you a poem - a poem I've found lying here under the rug under my bed-because one must if one wants to keep open a line of communica...

\section{[busy signal]}

...under the bed-yes under the bed — which, to my experience, is a lousy place if one wants something to be heard...or read...still on?

then breathe.

Thank you.

It's a messy scribble - you'll have to pardon the stops and starts-I suspect a doctor-no name. Title? Can't tell might be the first line-lined paper-suspect a student - no student of poetry it's clear-hear goes...

Oh, I recall my little Jon, the nights we spent of yesteryear, parties dragging on and on, music playing through the dawn, and swinging from the chandel...

\section{[busy signal]}

here it gets a little blurry — no matter - quite awful actually—no wonder it's hidden where it is - why keep it at all — fear of being forgotten I supposecontinues... 
Ah, he was young and so was I, as if strings from a puppeteer, made the child jump and fly, and swinging from the chandelier, fall from the bed and never die.

\section{[chuckles]}

Silly huh? - fall from the bed-whoa!

breathe

...sometimes

breathe

Not this bed! — couldn't break an ankle falling from this bed! — chandelier? Not in all the years I've lain here I...

\section{[busy signal]}

never seen a chandelier! Even with my eyes there has never been anything in that ceiling but a few cracks and an ancient hook-up there-over some. No matter. Limited and broken communication is only going to lead to distortions of what I'm seeing. You judge. But nothing like a chandelier I promise you! You can take that for truth, I'll witness. If ever there were a chandelier at all certainly no trace now - no, no trace now-you there? No trace now-breathing?

Then breathe.

Possibly there was something resembling light once-I wouldn't call it chandelier-perhaps stretched some-clumsy thing at that - certainly no chandelier if one was to try and call it one - hang from it — out of the question - just a hookno memory attached to this one though - neither good nor bad-not a one attached-

I'll swear on that account whatever the cost — didn't remove it myself if that's what you're thinking-didn't pull it out of the ceiling! That's what you're thinking! Breathe!

breathe

breathe

breathe 